\title{
KatHeRINe MANSILLA
}

Pontificia Universidad Católica del Perú

Resumen: El presente artículo quiere mostrar la proximidad entre la reflexión fenomenológica que Merleau-Ponty elabora en el artículo La guerra tuvo lugar (1945), y los relatos de José Carlos Agüero, en su obra, Los Rendidos (2015). Desde una perspectiva fenomenológica (pre-reflexiva), ambos autores describen la experiencia del dolor, la vergüenza y el perdón como la búsqueda de libertad y justicia. El texto se divide en dos partes. En la primera parte, describimos los discursos de justicia instaurados luego del conflicto armado interno y la necesidad de realizar la "époje", para describir los sentimientos de terror y vergüenza, que subyacen como fondo de esta vivencia compartida. En el segunda parte, apoyados en el conceptos de intersubjetividad e historicidad de Merleau-Ponty, definimos la libertad como la búsqueda de justicia, que solo puede comprenderse en la acción primordial de relación con los otros, a partir de la cual le damos sentido al pasado.

Palabras clave: Fenomenología, Maurice Merleau-Ponty, José Carlos Agüero, intersubjetividad, historicidad

Abstract: This paper seeks to show the proximity between the phenomenological reflection that Merleau-Ponty presents in the article "The War Has Taken Place" (1945), and the stories of Jose Carlos Agüero, in his book, Los rendidos (The Surrendered) (2015). From a phenomenological perspective (pre-reflective), both authors describe the experience of pain, shame and forgiveness as the pursuit of freedom and justice. The text is divided into two parts. In the first part, we present discourses of justice which were established after the Peruvian armed conflict (1980-2000) and the need of exercising the phenomenological "epochè" in order to describe the feelings of terror and shame that underlie as background of this shared experience. In the second part, supported by Merleau Ponty's concepts of intersubjectivity and historicity, we define 
freedom as the pursuit of justice, which can only be understood at the primordial action of being in relation with others, from which we give meaning to the past.

Keywords: Phenomenology, Maurice Merleau-Ponty, José Carlos Agüero, intersubjectivity, historicity

No hay purezas ni impurezas en una guerra, el horror es eso, horror. Hay que recuperarlo y describirlo y revivirlo y, luego, sacar sus consecuencias, mirarnos sin trucos con la mugre compartida o propia. Y a ver si podemos reconocernos.

José Carlos Agüero, Los rendidos ${ }^{122}$

José Carlos Agüero es un joven historiador peruano, hijo de miembros de Sendero Luminoso, que se ha aventurado a publicar, este año, una serie de reflexiones y relatos sobre el período de violencia desde sus propias vivencias. El libro ha sido titulado Los rendidos. En estos textos, el historiador hace pública su reflexión sobre la guerra, porque, para él, "lo vivido" es un asunto de justicia y, por lo tanto, es un tema público. Así, Agüero nos plantea discutir términos sedimentados sobre nuestras nociones de justicia, tales como "víctima”, "vergüenza”, “culpa”, “perdón”.

En 1945, a finales de la Segunda Guerra Mundial, Maurice Merleau-Ponty escribe un artículo titulado "La guerra tuvo lugar", como un intento de explicar y comprender el sentido del horror humano vivido en este período. El artículo tiene como trasfondo un análisis fenomenológico de la intersubjetividad y la justicia.

Lo que quisiéramos mostrar en este artículo es la proximidad entre los relatos recientes de Agüeroy los escritos de Merleau-Ponty sobre la guerra. Buscamos comprender cómo ambas reflexiones profundas -sobre el dolor, la vergüenza y el perdón- se entrelazan en una búsqueda de libertad, enmarcada en la idea fenomenológica de coexistencia humana como aquello que desborda

122 Agüero, José Carlos, Los rendidos. Sobre el don de perdonar, Lima: IEP, 20I5, p. I0I. En adelante, Los rendidos. 
al propio yo y obliga a pensar la libertad en un plano político. Así también, queremos hacer notar cómo, para ambos autores, la guerra muestra que la libertad de uno corre a la par con la de los demás y que, como dice MerleauPonty, uno no es libre solo ${ }^{123}$. Si la libertad aparece hoy en día, en términos normativos, como un derecho innato de todo individuo desde el momento de su nacimiento, lo que nos muestra el ámbito pre-reflexivo, del que nos habla la fenomenología, es que la libertad supone un entrelazamiento en y con los otros. En este sentido, los autores -Agüero y Merleau-Ponty- equiparan el perdón con un acto individual de libertad para resarcir en la historia colectiva las formas de entender la justicia. El perdón o la rendición no es un deber, sino la forma de replantearnos la libertad como una responsabilidad histórica con los otros y con nuestro pasado.

Esta presentación se divide en dos partes, las mismas que suponen, de cierto modo, el uso del método fenomenológico. En la primera, proponemos hacer epojé, retornar a las cosas mismas, "suspender" (no anular) los juicios de valor sobre la justicia instaurados en nuestra cultura, luego de los años de violencia interna en el Perú. Al respecto, es preciso aclarar que reconocemos la posición jurídica-social como importante para resolver los problemas que nos ha dejado este período de conflicto armado. No buscamos dar una lectura al problema desde o contra estas posiciones, sino que queremos encontrar, por debajo de ellas, un elemento central y unívoco que están olvidando dichos enfoques jurídico-sociales contemporáneos; queremos mirar, pues, pre-reflexivamente, en el fondo de todos ellos. En la segunda parte de nuestra presentación analizamos este retorno a las cosas mismas desde el plano fenomenológico del Lebesnwelt o el mundo-de-la-vida. Aquí, ayudados por el texto de Agüero y las reflexiones de Merleau-Ponty, describiremos aquellos elementos invisibles en nuestras relaciones humanas que solo se hacen visibles en la guerra. Precisaremos esta reflexión sobre dos conceptos claves que aparecen en la fenomenología de Merleau-Ponty: intersubjetividad e historicidad.

Antes de pasar a la exposición, quisiéramos mencionar algo sobre Los rendidos. Criticado o elogiado, dicho texto, publicado en mayo (y que va ya por la tercera impresión), es una invitación al debate y a la reflexión, también en la academia

I23 Cf. Merleau-Ponty, Maurice, "La guerra tuvo lugar", en: Sentido y sinsentido, Barcelona: Península, 1977, p. 217. En adelante La guerra tuvo lugar. 
filosófica. Para nosotros, esta presentación es una ocasión para conversar, una vez más, de aquella época de conflictos que aún nos cuesta mirar.

\section{§ 1. El retorno a las cosas mismas: la vergüenza}

Carlos Iván Degregori ha mostrado cómo los discursos hegemónicos, que se han instaurado antes y después del Informe Final de la Comisión de la Verdad y Reconciliación (CVR), muestran una confrontación permanente entre vencedores y vencidos ${ }^{124}$. Siguiendo esta dicotomía, Eduardo González ${ }^{125}$ explica cómo, desde las ciencias sociales y el derecho, se han buscado soluciones, sea desde el proyecto de los derechos humanos o desde los estudios sobre la memoria. Así pues, los analistas vinculados a los derechos humanos, en su lucha contra la impunidad, han planteado la dicotomía perpetrador-víctima, donde la víctima se identifica como la persona cuyos derechos fundamentales han sido violentados. Los intelectuales vinculados a los estudios sobre memoria identifican las narrativas existentes en el período de violencia, en torno a cómo narramos estos hechos, cómo vamos formando una memoria colectiva. En este enfoque, la víctima no se define jurídicamente, sino que tiene una identidad construida intersubjetivamente. Pero, en tanto el perpetrador tiene sus propias narrativas, se convalida a ambas, lo que podría resultar, desde otros puntos de vista, peligroso al momento de señalar responsables.

De estas dos posiciones, resulta una definición binaria del conflicto y-como explica Gonzáles- se ignora en esa distinción que los juicios morales (heroísmo, traición) solo son reservados para los que combatieron, obligando a las víctimas, en su mayoría población civil, a tomar una posición de pureza o inocencia durante el conflicto ${ }^{126}$. Entonces, como se puede apreciar, en esta

I24 Cf. Degregori, Carlos Iván, “Espacios de memoria, batallas por la memoria”, en: Revista Argumentos, III, No. 4 (2009), disponible en: http://revistaargumentos.iep.org.pe/articulos/ espacios-de-memoria-batallas-por-la-memoria/.

125 Cf. Gónzalez, Eduardo, "Sub-versiones. A propósito de Los rendidos de José Carlos Agüero”, en: Revista Argumentos, IX, No. 2 (20I5), disponible en: http://revistaargumentos.iep.org. pe/articulos/sub-versiones-a- proposito-de-los-rendidos-de-jose-carlos-aguero/.

126 Cf. ibid. Podríamos decir que esta es la posición que Agüero critica del libro de Gavilán, Lurgio, Memorias de un soldado desconocido: autobiografía y antropología de la violencia, Lima: IEP, 2012 . 
dicotomía sobre los estudios de violencia partimos de una "actitud natural"|27 interesada en solucionar institucionalmente los problemas de justicia y reparación. Sin embargo, no podemos decir que, luego de quince años de publicación del Informe Final de la CVR, hayamos asumido institucional y socialmente sus recomendaciones.

La fenomenología puede ayudarnos en este proceso truncado. Como disciplina filosófica, nos propone suspender la validez de nuestros juicios normativos y sociales y encontrar algo que subyace como suelo de todos estos paradigmas. Para mirar el trasfondo de estos, pensamos que los relatos de Agüero son profundamente inspiradores, puesto que conllevan a repensar nuestro papel social y político, oculto por el discurso dicotómico de la justicia ${ }^{128}$. ¿Cómo Agüero nos motiva a suspender la validez de nuestros juicios? El autor no se situará como el "guardián de una moral superior"|29; él rompe el discurso instituido porque, a pesar de haber trabajado en la CVR y de formar parte del Grupo Memoria del Instituto de Estudios Peruanos (IEP), siente una profunda vergüenza de lo vivido ${ }^{130}$. Este sentimiento emerge y pone en cuestión los discursos sedimentados; no busca negarlos, sino encontrar el fondo que los sostiene. Agüero quiere renunciar a los consensos y a los discursos de pos-guerra para mostrarnos qué es lidiar con el horror y preguntarnos, colectivamente, cómo sobrevivimos a él: "La vergüenza no es un sentimiento, es algo real, un mecanismo razonable, por eso no se puede evitar. No se trata de un momento de humillación, no es como caerse frente a un auditorio con gente. Esta vergüenza no requiere ser activada. Forma parte de cada cosa que haces y de cómo te relacionas con los demás. Se construye a sí misma por años, con cada mentira, silencio, secreto, con cada evasiva, cada relato o con los largos momentos de soledad"|31.

127 Entendida como en la fenomenología.

I28 Cf., por ejemplo, la nota "Los rendidos, un alegato contra la desmemoria" de Jairo Rivas, ex secretario de Consejo de Reparaciones a las Víctimas, publicada en: NoticiasSER.pe (http:// www.noticiasser.pe/I0/06/2015/cruce-de-caminos/cruce-de-caminos/“los-rendidos"-un-alegatocontra-la-desmemoria), o la nota "La batalla del hijo" de Renato Cisneros, publicada el 3 de mayo del 2015 en el diario La República (http://archivo.larepublica.pe/columnistas/que-sabe-nadie/ la-batalla-del-hijo-03-05-2015).

129 Los rendidos, p. 23.

I30 Cf. ibid., p. 24.

I3I Ibid., p. 20. 
El autor nos sitúa en los sentimientos que amordazan nuestra historia de violencia y de los que hemos preferido callar: la vergüenza, la culpa. Sus relatos exploran, pues, una pregunta personal (la suya): "ipuede la culpa heredarse, transformada en vergüenza por el origen y los antepasados?"|32. Y esa pregunta replica en nosotros de maneras distintas: ¿quiénes hemos sido y dónde nos hemos situado durante la guerra interna?, ¿quiénes estamos siendo ahora frente a nuestro pasado?

En ese mismo sentido, Merleau-Ponty explica que la guerra nos muestra la violencia como una condición de nuestra humanidad, pero que eso tiene un carácter de negación intrínseca. La guerra desvela la violencia humana que ha estado ahí, previamente a la guerra, y que, a pesar de que la educación nos haya librado por mucho tiempo de conductas pueriles, mantuvo pasivamente a la violencia en el convivir, en el que para otros sujetos, dice el autor, yo no era un hombre, sino un "francés"|33. La violencia invisible, en su estado soterrado y al mismo tiempo latente, convive con nosotros haciéndonos despojar al otro de su libertad. Dice Merleau-Ponty: "Si hubiéramos mirado mejor, habríamos encontrado ya en la sociedad del tiempo de paz, señores y esclavos, y hubiéramos podido aprender, cómo cada conciencia, por más libre, más soberana e irremplazable que se sienta, se fija y se generaliza bajo una mirada extranjera, se convierte en un 'proletario' o en un 'francés'. Pero ninguna servidumbre es tan visible como la de un país ocupado. Incluso aquellos entre nosotros que no estaban inquietados y continuaban pintado y escribiendo o componiendo poemas, experimentaban, volviendo a sus trabajos, que su libertad de antes corría a la par de la de los demás y que uno no es libre solo. Si habían podido antes sentirse alegres y dueños de su vida, esto no era posible más que en una cierta atmósfera, aprendían a conocer entre cada conciencia y de todas las demás este medio general donde pueden comunicar y que antes no tenían nombre en sus filosofías"134.

El gran aporte de la fenomenología a las ciencias humanas es proponer una nueva mirada desde la epojé, la cual consiste en poner "entre paréntesis" todos los juicios supuestos de las ciencias para reconocer que los paradigmas

132 Ibid., p. 118.

I33 Cf. La guerra tuvo lugar, p. 215.

$88 \quad 134$ lbid., cursivas nuestras. 
científicos (sociales) provienen de una construcción intersubjetiva que se ha ido dando históricamente y que se ha ido sedimentado en la sociedad como verdades de hecho. En la fenomenología, para superar el conocimiento sedimentado, el científico (social) hace epojé y descubre cómo las construcciones teóricas emergen de una capa pre-reflexiva, donde se muestran los núcleos de significación que no se habían puesto en duda. En este plano, que llamaremos pre-reflexivo, nos descubrimos en un fondo opaco de naturaleza, donde encontramos los comportamientos de los hombres como familiares entre sí.

Entonces, desde estenivel pre-reflexivo (también llamado pre-personal, impersonal o irreflejo), Merleau-Ponty habla de una generalidad primaria o un anonimato, al cual estoy adherido y en el que confío. La generalidad es la coexistencia con los otros, con sus objetos y sus actos ${ }^{135}$, es la historia a la que pertenezco y en la que mis actos y mis pensamientos hallan su sentido, es aquello en lo que mi cuerpo se apoya para participar de la convivencia con otros sujetos. En ese sentido, dice Merleau-Ponty que "la generalidad interviene ya, nuestra presencia a nosotros mismos está ya mediatizada por ella, cesamos de ser pura consciencia, desde que la constelación natural o social cesa de ser un eso informulado y se cristaliza en una situación, desde que tiene un sentido, eso es, desde que nosotros existimos"136.

La descripción fenomenológica del anonimato revela un nivel de intimidad desde el que hemos venido comportándonos y sobre el que nos apoyamos para dar sentido a nuestras acciones. Llamémosle a este nivel, anónimo e invisible, la vergüenza de una historia compartida, conflictiva, de prejuicios y abusos, de los que hemos tomado parte - muchas veces- sin proponérnoslo individualmente. Según Merleau-Ponty, la coexistencia se presenta sobre un fondo de historicidad no escogido, en el que se da la alienación de las conciencias ${ }^{137}$,

I35 Cf. Merleau-Ponty, Maurice, Fenomenología de la percepción, Barcelona: Península, 1997, p. 360 . En adelante, $F P$.

I36 Ibid., p. 457.

137 “(...) cada uno de nosotros en la coexistencia se presenta a los demás sobre un fondo de historicidad que no ha escogido, se comporta para con ellos en calidad de 'ario', de judío, de francés, de alemán; las conciencias tienen el extraño poder a alienarse y de ausentarse de sí mismas, que están amenazadas desde el exterior y tentadas desde el interior por odios absurdos e inconcebibles y que, si un día los hombres deben ser hombres los unos para con los otros, y las relaciones de las conciencias volverse transparentes -si la universalidad debe realizarse-, será en una sociedad en la que los traumatismos del pasado habrán sido liquidados y en la que 
porque estas no confrontan el pasado o, mejor dicho, no quieren responder al pasado reinventándolo. Para Merleau-Ponty, el lenguaje (los gestos, las palabras, la cultura, los comportamientos) se sedimentan y convivimos con ellos de forma natural. Solo se visibilizan cuando tomamos conciencia histórica de todo lo olvidado.

A través de la vergüenza, Agüero hace un esfuerzo por mostrarnos lo olvidado (irreflejo), lo queyace en el anonimato. Con la vergüenza rompemos con la actitud natural, con lo instituido. La epojé se traduciría aquí como el reconocimiento de que estamos siendo cómplices de un daño histórico y cuyo olvido se filtra en nuestras visiones de justicia. Dos ejemplos nos podrían ayudar a explicar lo que venimos argumentando. En el primero, Agüero cuenta que cuando los policías intervenían su casa buscando a los terroristas (su familia), los vecinos solían delatarlos para protegerse (eso era comprensible). Pero una vez, una mujer muy pobre, a la que su madre solía ayudar mucho, a la que invitaban a comer y de quien cuidaban con mucha atención, fue la que los señaló con más odio y más rabia. Él piensa sobre esta mujer: "Tal vez solo quiso existir. Y esa fue su oportunidad. Su único momento de dejar de ser la última rueda de este coche horrible de la pobreza. Había entrevisto un nivel más abajo. Nosotros, los que además de pobres, estábamos sucios"|38. Se quiebran aquí valores o relaciones, ila lealtad se da con los principios o con los amigos?, iestamos realmente actuando desde los principios?, ipor qué el odio? Se describe aquí una situación que nos pone a todos "sucios", las barreras de lo justo e injusto se confunden en las jerarquizaciones sociales de nuestra historia: soy mejor respecto a $x$; si soy el último eslabón de la jerarquía económico-social, puedo ser mejor que "estos terroristas". En este caso, hay una especie de decencia en la mujer que al mismo tiempo nos muestra su odio y su hartazgo, su posibilidad de "ser vista", y esto se hace más claro en un escenario de horror como es la guerra. El segundo ejemplo no es de Agüero, sino que nos ha sido narrado por terceras personas, pero va en esta misma perspectiva: en una reunión organizada por instituciones de derechos humanos, las víctimas debían elegir quién irá a un congreso en Canadá para contar su experiencia como familiares

de entrada se hayan realizado las condiciones de una libertad efectiva. Hasta que no se llegue a esto, la vida social seguirá siendo este diálogo y esta batalla de fantasmas en la que a menudo corren verdaderas lágrimas y verdadera sangre" (La guerra tuvo lugar, p. 218). 
de desaparecidos. Dos mujeres terminan discutiendo sobre quién de ellas tiene más familiares desaparecidos y, por lo tanto, "es más representativa". ¿Estamos mostrándonos, estamos existiendo para los demás desde el quién ha sido más humillado?

¿Qué significa visibilizar la vergüenza? La vergüenza se puede vivir de muchas maneras y no todas suponen "instituir" nuevos lenguajes. Algunos pueden recubrir la vergüenza para no sentirse ni cómplices ni culpables, sino solo víctimas que, por lo tanto, deben ser tratadas como tal. Otros, incómodos en el papel de formar parte del rol de perdedores, buscan encontrar elementos de reivindicación de su situación ("no todo pudo ser tan malo, la lucha tiene que tener algún sentido"). Otros se niegan por completo a reconocer la vergüenza y se ponen rápidamente en el rol de lo "políticamente correcto" que, bajo los principios democráticos, "saben" quienes son los enemigos y los culpables ${ }^{139}$. Particularmente, Agüero usa como camino de irrupción su vergüenza, la hace pública y así "renuncia a la autoprotección", se ve descubierto, vive vulnerado. Agüero reconoce el error de sus padres, ellos hicieron mal, sus decisiones hicieron daño público. Dice también, que él -jurídicamente hablando- no tenía la culpa de nada, porque era un niño de padres terroristas, una víctima, aunque le de vergüenza también serlo. Pero el escritor no se queda en ese rol socialmente asignado, sino que quiere ir más alláy mostrar esa vergüenza como propia y, al mismo tiempo, como la generalidad social: "Yo planteo el camino inverso. Ser una víctima por primera vez, para poder tener la oportunidad de perdonar y, luego, rendirme. Dejar de serlo para entregarme completamente a la censura, la mirada y la compasión de los demás" ${ }^{40}$. Haciendo pública su vergüenza, Agüero resignifica el lenguaje de los años de violencia porque "hace explotar" nuestra vergüenza en nuestros propios rostros lectores, como un camino de reconstrucción pública para la ética y la política.

Las reflexiones de Merleau-Ponty tienen mucho en común con estos relatos. Como profesor universitario de filosofía y obligado a ir a la guerra contra Alemania para defender su país, Merleau-Ponty reconoce que, en este período, los

I39 En varias partes del texto puede entreverse la insatisfacción de Agüero respecto de los paradigmas académicos y de la ética en la que se sitúan los estudios de posguerra y que el autor llama "el discurso políticamente correcto" (cf. ibid., pp. 24 y 35, por ejemplo).

140 lbid., p. 120. 
intelectuales franceses no conocían el horror y que vivirlo supuso otra forma de comprender el mal|41. Es en esa situación que uno reconoce la complicidad de las relaciones humanas de las que uno, antes de la guerra, ya era partícipe: "Es así como la historia solicita y despide a los individuos; es así como, viendo las cosas desde cerca, no se encuentran nunca culpables y siempre cómplices; es así como todos nosotros tuvimos nuestra parte en los sucesos de 1939. Entre nuestros alemanes y nosotros sólo hay la diferencia de que ellos tenían ya a la vista el nazismo y nosotros todavía no. Ellos no podían ignorar el uso que se hacía de sus vidas, nosotros todavía no habíamos aprendido ese juego"|42.

En síntesis, Agüero y Merleau-Ponty muestran que la violencia guarda una relación profunda con los sistemas de justicia. Dicha relación solo puede ser vista desde lo pre-reflexivo, donde yacen nuestras relaciones de co-existencia que se han sedimentado históricamente. En nuestro caso peruano, los paradigmas de justicia se sedimentan sobre el horror que queremos hacer "pasar desapercibido" porque duele, pero que, sin embargo, cuando uno lo logra mirar nos muestra -sin tapujos- una posición que tenemos sobre los otros y sobre uno mismo. En nuestro contexto nacional, ese es el rol de la obra de Agüero: es instituyente porque busca pensar las vivencias, o decirlas, como nunca antes se han dicho, sin claridad ni evidencia, sin pretensiones universales, sin objetivos claros, sino sabiéndose situado en un lugar y momento desde el cual buscar conversar, reconociendo que su perspectiva de los hechos forma parte de la generalidad social. Debemos entonces entender este camino que nos proponen los autores: el hacer público algo (en este caso la vergüenza) es un acto de reflexión que supera el dolor que siempre queremos evitar, es un acto de reflexión pública porque permite la comprensión de la experiencia como participante en una historia de guerra y conflicto.

I4I "Sabíamos que existían campos de concentración, que los judíos eran perseguidos, pero estas certezas pertenecían al universo del pensamiento. No vivíamos todavía en presencia de la crueldad y de la muerte, nunca se nos había puesto en la alternativa de sufrirlas o de afrontarlas" (La guerra tuvo lugar, p. 21I). 


\section{\$ 2. El mundo de la vida, el rendido y la libertad}

Optando por el papel del rendido y las contradicciones que eso supone (no fui terrorista, pero participé de la guerra; soy familiary amigo de terroristas, pero ellos hicieron mal), Agüero reclama ser una víctima escuchada. Escucharlo a él es escuchar su tejido social y afectivo, su mundo de la vida (que también es nuestro, aunque posiblemente desde una posición distinta). A partir de sus palabras, conocemos a su madre que protege a sus hijos de la guerra, pero que cree que Sendero Luminoso es una opción para que sus niños no tengan que luchar en el futuro; conocemos a su padre como un militante trágicamente asesinado en el Frontón, quien no fue juzgado ni enterrado; así también hemos conocido a la abuela, a los amigos terroristas de paso, a los vecinos pro-Sendero en cada mudanza familiar, a los espías del partido, a los policías pobres que luchaban en el conflicto; en fin, a los que siempre estaban/ están ahí pero queríamos/queremos ver como enemigos -o, peor aún, como "monstruos"- para salvación nuestra. Agüero repite en varias entrevistas que lo que ha querido expresar en su texto es una denuncia de los estereotipos de la guerra: esa gente (su familia, sus amigos) eran personas (como todos) y no "monstruos", "cargaban agua”, "hacían fiestas", trabajaban, estudiaban y, sin embargo, sus ideas hicieron un gran daño nacional. Agüero exige no olvidar, sin justificar, claro está, que su respuesta "revolucionaria" nacía de una historia de injusticias más antigua que no se había ni se ha resuelto.

Merleau-Ponty explica, al final de la Fenomenología de la percepción, que el pasado nos solicita nuestra libertad, pues si fuese lo contrario esta nacería de la nada y la historia iría a ninguna parte. La libertad es el proyecto humano concreto de dar sentido a una historia, donde aquella es motivada por esta última $^{143}$. La libertad individual es un proyecto concreto de futuro, que solo puede ser elaborado en la coexistencia social de la generalidad, antes que en cualquier decisión individual. Rendirse y perdonar es, de este modo, un proyecto de cura que busca darle un sentido particular a nuestra historia en nuestro devenir político. 
Es importante mencionar que con "político" nos referimos al nivel irreflejo que podría ser explicitado desde la propuesta de Chantal Mouffe sobre la agonía democrática. Mouffe propone lo político como la dimensión de coexistencia en la que convergen las identidades en oposición o conflicto y que, a su vez, alimentan o motivan la política. Esta última es el lugar del discurso u ordenamiento institucional, donde las oposiciones encuentran una estructura en la que son reconocidas. En el plano político la diferencia no desaparece, más bien se mantiene como un motivo de interés de la política; esta, en cambio, se "hace cargo" del estrato subyacente de oposiciones que lleva "potencialmente" esta contradicción ${ }^{144}$. Hay una relación de motivo-motivado ${ }^{145}$ entre la política y lo político, así como hay una relación motivo-motivado entre la historia y la libertad. De ese modo, la "rendición" supone una toma de posesión distinta de nuestra propia temporalidad o, dicho de otra manera, la rendición es motivada por la historia reflexionada y la historia se hace nueva con esta rendición. En palabras de Merleau-Ponty, es como "un momento en que el sentido que se dibuja en lo impersonal (on), y que no era más que un posible inconsistente, amenazado por la contingencia de la historia, es recogido por un individuo"146.

Hay dos características centrales en la actitud del rendido que nos interesan para la fenomenología. La primera tiene que ver con el concepto de intersubjetividad y la segunda con el de historicidad. Miremos esto detenidamente.

Sobre la intersubjetividad, Merleau-Ponty nos dice que en el plano pre-reflexivo no nos encontramos con una conciencia de sí mismo, sino que uno es para el otro, como "colaboradores de una reciprocidad perfecta". Merleau-Ponty explica esta reciprocidad desde la infancia: los niños "no tienen la ciencia de los puntos de vista (...) los demás son para él miradas que inspeccionan las cosas, tienen una existencia cuasi mareal, hasta el punto de que un niño se pregunta por qué las miradas al cruzarse, no se rompen"|47. Hay que entender que el niño vive en un trasfondo de significados sin someter a crítica sus pensamientos, él es a través de los otros. Por eso, para el fenomenólogo, el sentido del sí mismo se da posteriormente en los niños, en su impetuosa

144 Cf. Mouffe, Chantal, La paradoja democrática, Barcelona: Gedisa, 2000.

I45 Lo que Merleau-Ponty define como Fundierung.

146 FP, p. 457.

147 lbid., p. 366. 
búsqueda de ser individuos. En el plano de entrecruzamiento que hemos llamado generalidad, anonimato o Naturaleza, la intersubjetividad es la situación común por la que nos comunicamos con los demás que me son familiares, tal como sucede en el niño. Pertenezco a este todo general en el que mis padres (o cuidadores) son el mundo.

Agüero narra así su infancia: el niño se autoconoce indesligablemente desde su fondo, es decir, su familia senderista, cuyo fondo mayor es un país injusto. Solamente mientras tenga más experiencia de la profundidad del fondo, el sujeto puede ser impulsado por este para construir su individualidad. Narra el historiador: "La guerra era el marco de fondo de nuestra vida familiar, nuestra normalidad, como ir al colegio, acarrear agua, salir a jugar. (...) Que te eduquen desde niño para mirar la pobreza y para que te duela, acaba por tener resultado y se vuelve una especie de naturaleza y sentido común. Ahora, cuando se dicen o escriben cosas así, suenan patéticas y bobas, más si se dicen en público. Pero no veo otra forma de describirlo. (...) Lo cierto es que esa fue mi manera de relacionarme con mi mundo, creo que en parte así eran también los adultos que entonces militaban en Sendero. Sólo que quizá por ser niño, todas estas sensaciones y aprendizajes se convirtieron en mi lenguaje materno, mi ADN"|48.

Para entender la complejidad de nuestra libertad, su punto de vista pasa por esa generalidad en la que ha nacido, que es -para él- un comportamiento "natural". El primer otro -la madre, el padre- es la entrada al mundo que uno asume tácitamente como el estilo de lo social. En el mundo de Agüero, "hacer la guerra" era, por lo tanto, un proyecto con sentido. El después de la guerra es más complejo y crítico: iqué pasa si el proyecto es un fracaso?, ¿qué sucede si yo y mi familia somos los perdedores y los culpables para el resto del país?, ¿qué pasa ahora que para “los demás” yo soy una víctima? Solo inmediatamente después de narrar la muerte de su madre, Agüero describe el desmoronamiento de mundo circundante: "Yo había sido educado en valores que no tenían sentido, que hubieran servido de haberse instaurado el socialismo utópico. Mis habilidades sociales eran inservibles, no más solidaridad, no más sufrir por los demás, no más ofrecer amparo. Pero uno no apaga esas 
cosas como si fueran botones de una máquina. Mi lenguaje tampoco servía ya, no solo era poco práctico, sino que era tabú, era objeto de sospecha. Mis lecturas, mis libros preferidos, todos inservibles. Mis amigos muertos. Mi familia dividida. Mis hermanos separados e igual de confundidos. Pero sobre todo me sentía solo. Esa extraña sensación de haberme quedado de pronto como el único habitante del planeta que no existió”|49.

Después de la guerra, no solo el mundo deja de tener sentido para el autor, sino también para su lector, desde su propia forma de haber vivido el conflicto armado. Sin embargo, la narración ha revelado algo que se mantiene en esa generalidad aún compartida y que se vive nuevamente de formas sutiles pero llenas de horror: las estructuras sociales son todavía injustas, inadmisibles. Ahora bien, si uno parte del sentimiento de posguerra universalizando el rechazo a la barbarie, puede que ignore los "rostros" de los otros afectados en este mundo injusto. Merleau-Ponty nos sugiere tener cuidado con la pretensión de que compartimos el “mismo mundo" y, por ello, nos propone el concepto de intermundo. Con él, el fenomenólogo quiere explicar que somos un ego y un alter ego, con posiciones y situaciones de vida distintas, pero que podemos coexistir "recíprocamente". Lo que entiende Merleau-Ponty por "reciprocidad" es el ejercicio de una libertad que no es el sentido moderno y convencional de la autonomía, sino que supone que solo puedo ser libre responsabilizándome de la libertad del otro. Dice el filósofo: “(...) yo no tengo, en rigor, ningún terreno común con el otro, la posición del otro con su mundo y la posición de mí mismo con un mundo constituyen una alternativa. Una vez el otro pro-puesto, una vez la mirada del otro sobre mí, al inserirme en su campo, me ha despojado de una parte de mi ser, se comprende muy bien que yo no pueda recuperarla más que entablando una relaciones con el otro, haciéndome reconocer libremente por él, y que mi libertad exija para los demás la misma libertad”|50.

Entonces, hay una relación dialéctica de la libertad o, como lo propone el fenomenólogo, una relación de Fundierung: la libertad del otro es el motivo de mi libertad, puesto que no tiene sentido ser libre sin que otro no lo sea y viceversa. La invitación a rendirse, desde esta postura fenomenológica, es un 
motivo para declararme yo también responsable de lo que vi, veo o no quiero ver, de lo que hago o no quiero hacer, pero debo hacerlo porque el otro me interpela desde el pasado compartido. Este es el núcleo central de la justicia, tal como lo manifiesta Agüero: "Porque en una guerra el daño es un tema central para comprender las relaciones. Funda un mundo de víctimas. Un pueblo está habitado por víctimas. Esa es la primera condición para acercarse a él. El país, el mundo entero es una fosa común. Sin esa honestidad, se cae en la arrogancia del intelectual o del esnob, o peor aún, en un nuevo vicio de la institucionalidad de derechos humanos, lo fue el activismo narcisista antes: la tecnocracia"|5|.

La segunda característica que describe las relaciones del mundo de la vida es la de la historicidad. Para Merleau-Ponty, la historia no puede entenderse como una serie de sucesos históricos causados por otros hechos que se concatenan entre sí. Tampoco cree Merleau-Ponty que haya una determinación histórica: el hombre está condicionado por el tiempo, por su campo de relaciones concretas, pero de la misma manera está abierto a lo posible, a resignificarse, porque es un "proyecto inacabado". En la historicidad también se puede entrever la relación de motivo-motivado, porque yo actúo motivado por el pasado para hacer el futuro. Ese movimiento se entiende aquí como responsabilidad. En otros términos, la responsabilidad es el ejercicio de nuestra temporalidad humana, es la invitación que nos hace el pasado en tanto motivo, pues más allá de si ha habido o no un hecho de guerra, uno debe responder al pasado en el presente. A diferencia de la filosofía kantiana, que propone al tiempo como una forma a priori de la sensbilidad, Merleau-Ponty explica el tiempo como "reprise" (retomar) el pasado y a través del presente hacerlo futuro. En otras palabras, el tiempo es un movimiento dialéctico o de Fundierung, donde uno recoge el pasado y le da sentido. Dice el fenomenólogo: "la temporalización no es una sucesión (Nacheinander) de éxtasis. El futuro no es posterior al pasado, y este no es anterior al presente. La temporalidad se entiende como el futuro-que-va-al-pasado-viniendo-al-presente"|52. Así entendido, el tiempo es "retomar" (como movimiento, producción de sentido). Entonces, podemos pensarnos como sujetos que producimos o hacemos el futuro retomando el pasado, como el impulso de nuestra propia libertad.

I5I Los rendidos, p. 48.

152 FP, p. 428. 
Ahora bien, icómo pasamos de esta temporalidad del sujeto a pensar la historia? La historia, para Merleau-Ponty, es el inter-mundo, pues este no existe sino es una posibilidad, una "verdad por hacer", por crear. La historia supone los movimientos de retoma de nuestro pasado. Pensemos entonces, icómo podríamos entender el intermundo para nuestro país? Nuestra sociedad, que fácilmente etiqueta, desprecia y agrede al otro "diferente", tiene la tarea del "rendimiento" para la construcción del intermundo. Si asumimos esta tarea que propone Agüero, reconocemos que -efectiva e ineludiblemente-cada uno es diferente al otro, pero que el pasado nos está exigiendo comprenderlo, "escucharlo"; más allá de si uno cree que el comportamiento del otro es "reprobable", quisiera entender su punto de partida, el "cómo" y el "por qué" de sus valores, creencias y acciones. $Y$ en esa experiencia de reflexión profunda, reconocemos pues que estamos entramados en unas estructuras injustas para ambos. Merleau-Ponty expresa lo mismo en sus reflexiones sobre la guerra: "La guerra y la ocupación nos han enseñado solamente que los valores siguen siendo nominales, y que no tienen ningún peso sin una infraestructura económica y política que los haga entrar en existencia. Es más, que los valores no son nada, en la historia concreta, sino una manera distinta de designar las relaciones entre los hombres según éstas se establezcan por el modo de su trabajo, de sus amores, de sus esperanzas y, en una palabra, de su coexistencia"|53.

Merleau-Ponty nos plantea, desde el ámbito pre-reflexivo, una apertura hacia el otro que no se basa en una serie de valores o ideales compartidos. Lo irreflejo, en tanto condición de posibilidad de mi reflexión, me hace ver al otro sujeto "encarnado" en el mismo mundo en el que él y yo co-habitamos. La temporalidad humana (la historicidad) nos hace saber que el otro se mueve como yo y que tampoco podrá ser un ser completo. Impulsado por su pasado, crea su futuro, integra y transforma su historia. No es pues un sujeto cerrado, es un sujeto "posible", "inconcluso"; del mismo modo, el mundo es "inconcluso", pues tiene una "herida abierta" (dehiscencia) que es el tiempo en tanto motor de su propia transformación. 
Gracias a las explicaciones de Merleau-Ponty sobre la historicidad y al relato de Los rendidos podemos pensar que la vergüenza colectiva, aquella que se reflexiona y se hace pública, aparece como el intermundo. Por eso mismo, ellas exigen reflexionar sobre la historia y hacer el futuro desde un punto de vista distinto, considerando a todos los involucrados como parte de ese intermundo: "Los enemigos. Los culpables. Mis padres lo fueron. También lo fueron estos políticos. Los soldados que mataron a senderistas y los senderistas que mataron a policías y soldados. Los niños colocados en situación de matar y violar. Los torturadores, jóvenes pobres que tuvieron que quemar cientos de cadáveres y enterrarlos atrás de cuarteles para que nadie pueda encontrar más. Los mandos senderistas que por escarmiento, por pedagogía y para ahorrar munición mataron con piedras, hueso tras hueso roto, a sus enemigos en campos y barrios. ¿Dónde pueden los enemigos hallar su reflejo? ¿Es en el conocimiento mutuo de su suerte desgraciada? ¿En el mínimo reconocimiento de que también el otro ha padecido? ¿En lo absurdo de un orden que nos coloca como las sombras asesinas de cuerpos que son nuestro reflejo? (...) Mi enemigo, que sumergido en mí, duerme porque en la práctica, no es sino otra forma de mi ser"|54.

A modo de conclusión de esta presentación, diremos que la coexistencia no puede ser ni agotada ni sintetizada, sino solamente comprendida en su "lateralidad" (ya no universalidad). En la coexistencia tengo características, historias compartidas que trascienden mi propia síntesis del mundo. En ese sentido, el otro me desborda y me trasciende, y con ello descubro que el mundo nunca es solo mío y tampoco nunca es solo del otro. Somos cómplices del inter-mundo, lo que hacemos en el tiempo se hace en esa relación de motivo-motivado. Para relacionarme con mi futuro aquí y ahora, solo puedo saber que lo construyo en diálogo con otro sujeto, que exige mi descentramiento, así como yo "violento" su centralidad egológica.

Entonces, el libro de Agüero aparece como un motivo para construir un espacio de reflexión de lo que Merleau-Ponty llama intermundo, es decir, de la posibilidad de experimentar una solidaridad con el otro comprendiéndonos históricamente, de saber que estamos viviendo en una sociedad que es injusta 
y donde muchos pretenden invisibilizar esas estructuras sociales que violentan y dañan y que, por tanto, son vergonzosas. La vergüenza está ahí, se mantiene en nuestro presente, en nuestras desigualdades económicas y sociales, en el no escuchar a otros ciudadanos, o en las diferencias que hacemos privilegiando solo para algunos derechos civiles, políticos y económicos. Y, sin embargo, lo histórico nos plantea posibilidades y motivos para "hacer" algo sobre estas brechas profundas que existen entre nosotros.

Queremos terminar con una cita de Agüero que sirva como apertura a la reflexión de aquello que hemos querido mostrar en esta ponencia: la posibilidad de hacer un ejercicio individual sobre la vergüenza y el perdón como un punto de partida para la reflexión de la justicia. "Quizá esta necesidad de rendirme, de entregarme, es una forma de perdón. Nadie tiene que pedirlo, ni aún que desearlo. Ni siquiera debo querer otorgarlo (...). Pero sé, mi perdón no vale nada. No ayudará a la paz. Ni mil perdones ayudarían a que la paz no se agotara en la sangre de miles de personas que estallan a diario como si sus cuerpos se hubieran cansado de contenerlos. No hay paz en el perdón. Solo la prolongación de una entrega. Y una fe en los demás que no será satisfecha”|55. 